\title{
Improving Urban Mobility Management Case Study of Rome
}

\author{
Antonio Musso and Maria Vittoria Corazza
}

\begin{abstract}
Congestion, energy consumption, pollution, and the need to increase transport system sustainability are top-priority problems in urban areas. Most European cities are beset with these issues; hence, the European Commission financially supports projects aimed at reducing the negative effects of vehicles on the environment by increasing accessibility, optimizing economic resources in transport management, and improving citizens' quality of life. Presented are the main findings of one of these projects, Multi-Initiatives for Rationalised Accessibility and Clean Liveable Environments (Miracles), which focused on the measures implemented by the Rome municipality during the project, including incentives to attract passengers to transit and disincentives to the use of private cars. In particular, the most relevant aspects, such as restriction of vehicle access to the city center, road pricing, goods delivery reorganization, and the development of collective taxis, are analyzed because of their innovative features and their potential to achieve improvements. Also discussed is the suitable methodology, applied in the Rome case study, for controlling and validating all the implementation steps. Particular attention was paid to the simulation of scenarios that can be used to assess the feasibility of pricing-related measures and how they can affect the built environment. In conclusion, the paper outlines users' reactions to the restriction policy changes.
\end{abstract}

Environmental problems linked to mobility, congestion, and energy consumption, along with the need to meet more sustainable requirements in local transport systems, prompted many European cities to revise their mobility policies. Thanks to European Community support, many municipalities have had opportunities to implement strategies, policies, or sets of measures, in compliance with the laws of local areas, local social and political situations, and available local resources, to revise their mobility policies. The Multi-Initiatives for Rationalised Accessibility and Clean Liveable Environments (Miracles) demonstration project enabled Rome to apply a set of integrated measures at the same time as three other cities: Barcelona, Spain; Cork, Ireland; and Winchester, United Kingdom. Miracles is funded by the European Commission. It is part of a cluster of demonstration projects called Civitas (City Vitality-Sustainability), a major new urban transport initiative supporting demonstration projects in 19 cities across Europe, and is a key element of the new strategy on clean urban transport prepared by the Transport and Energy Directorate General of the European Commission. Each city participating in Civitas implements a set of measures in different domains, from the

Faculty of Engineering, DITS-Department of Hydraulics, Transportation and Roads, University of Rome, La Sapienza, Via Eudossiana 18, 00184 Rome, Italy.

Transportation Research Record: Journal of the Transportation Research Board, No. 1956, Transportation Research Board of the National Academies, Washington, D.C., 2006, pp. 52-59. infrastructural to the telematic domains, over a 4-year period (2002 to 2006) and asks local evaluators to assess the progress achieved in the implementation process and project goals using a common methodology (summarized below). A dedicated research team, the Monitoring and Evaluation of Transport and Energy-Oriented Radical Strategies for Clean Urban Transport (Meteor) Project, compares the results achieved in the cities participating in Civitas. The members of Meteor are appointed by the European Commission to assess the transferability of best practices and results to cities not participating in Civitas. Investigations on comparisons are under way, and the transferability and the preliminary results were expected by the beginning of 2006 .

The shared objectives of the cities participating in Miracles to improve their citizens' quality of life were a reduction of pollution from traffic, an increase in accessibility, and the optimization of transport management.

This paper deals with the Miracles implementation process in Rome and describes the most relevant measures aimed at steering mobility issues toward more sustainability-based policies, together with key findings. In particular, it stresses the need to approach mobility problems correctly by using a control methodology, at the theoretical level, and by using concerted actions based on incentives to attract passengers to transit and disincentives to the use of private cars that combine traffic restraint and the provision of alternatives to the use of private cars at a practical level. The paper also illustrates the current ability of a city to underline the significance of Miracles interventions on a complex built-up environment, like that in Rome. In conclusion, it classifies the actions and related objectives used to promote the use of transit and to discourage the use of private cars and also focuses on some of the most effective measures.

\section{CONTEMPORARY ROMAN CONDITIONS}

Environmental safeguards and integrated strategies to fight congestion phenomena in urban areas have become more and more mainstream issues on the Italian political agenda. Two general approaches were adopted: (a) officials have introduced emergency measures to control air and noise pollution rates in cities to safeguard public health and $(b)$ long-term integrated programs have been initiated to improve public transport and, hence, progressively reduce the number of private cars causing congestion and pollution.

Rome's structural features and transport patterns require that both approaches be adopted. The ancient, historic city center has narrow streets; its semicentral areas and suburbs, which were created to meet housing demand, are connected by only two underground lines and a large bus network. 
This public transport system is not able to meet Roman citizens' demand in a satisfactory way; therefore, in the past few years citizens have become addicted to private vehicles, leading to increases in the numbers of cars, mopeds, and motorcycles. According to Rome municipality data, the 2002 modal split in the Rome metropolitan area was as follows: $20 \%$ collective transport, $48 \%$ private cars, $11 \%$ two-wheelers, and $21 \%$ pedestrians and others. The total number of vehicles circulating throughout the $44-\mathrm{km}^{2}$ area of the city, with the exception of about 2,000 public buses circulating daily, is about $2,470,429$; they are mainly private cars $(1,853,546$ vehicles) and two-wheelers (514,766 mopeds and motorcycles) (1).

In addition, many private cars are old (with an average age of 8 years), inefficient, and highly polluting. This has a major impact on pollution levels, particularly in the city center, where pollution jeopardizes citizens' health, as well as the conservation of historic landmarks and, more generally, the city's appearance.

The facts mentioned above become more striking when they are considered in the context of the overall motorized vehicle ownership rate. In Rome, this rate, including that of two-wheelers, is one of the highest in Europe, with a current index of about 830 [(number of vehicles/number of inhabitants $) \times 1,000$ ]; this index increased by $11 \%$ between 1989 and 1995, largely as a result of a sudden rise after an Italian law provided state incentives to scrap old cars and replace them with new ones. It is noteworthy that such a high car density goes hand in hand with high values for two-wheeled vehicles; the index for two-wheelers rose from $191 \%$ in 1999 to $198 \%$ in 2000, and the two-wheeler ownership rate is currently about one two-wheeled vehicle for every five inhabitants.

Engine emissions data in the city area are based on several indicators: carbon monoxide (CO), volatile organic compounds (VOCs), nitrogen oxide $\left(\mathrm{NO}_{\mathrm{x}}\right)$, small particulates [particulates less than or equal to $10 \mu \mathrm{m}$ in aerodynamic diameter $\left(\mathrm{PM}_{10}\right)$ and total suspended particulates], and benzene. The levels of all these pollutants have slightly decreased over the past 2 years, in keeping with the national trend, partially as a result of the previously implemented spot measures and also thanks to other national policies aimed at global renewal of the private car fleet.

Among all the parameters taken into consideration, particulates raise a major concern. Indeed, $\mathrm{PM}_{10}$ levels are very high and are often close to the alert level $\left(50 \mu \mathrm{g} / \mathrm{m}^{3}\right)$ and above the national quality standard $\left(40 \mu \mathrm{g} / \mathrm{m}^{3}\right)$. Their levels are also higher than the European standard $\left(20 \mu \mathrm{g} / \mathrm{m}^{3}\right)$. The reasons for such poor performance can be linked to weather conditions and traffic. Rome has long winters with few rainy days and not much wind, so pollution levels remain high. Above all, chronic traffic congestion negatively affects air quality. The main sources of particulate pollution (1) are the extremely large number of private cars, many of which do not have catalytic converters; the very small number of ecologically friendly cars; and the old ages of buses as well as the old ages of mopeds and motorcycles.

\section{RESEARCH, STRATEGIES, AND INNOVATION}

The current situation called for a revision of the transport policy, the aim of which was to increase the rate of use of sustainable modes of transport and heighten the public's awareness of the measures to be implemented. Moreover, the participation of the municipality in the Miracles project allowed this change to be supported by an overall methodology that could be used to evaluate the suitability of the project realization process.

\section{Methodology}

For the city of Rome, the implementation of measures targeted at reducing the massive rate of car use and promoting the use of transit required an initial phase of study to assess the feasibility of these objectives and to evaluate the likelihood of realizing the project goals. The philosophy behind the implementation of each measure is not merely to enforce a set of regulatory tools to avoid bumperto-bumper traffic conditions but also to create a more livable situation in Rome.

Such an ambitious plan, which required complex surveys and measurements and which was influenced by a wide array of different factors, called for a methodology that was capable of analyzing and validating all of the steps in the implementation process and controlling external factors. Accordingly, two main evaluation phases were proposed: the ex ante and the ex post phases. The ex ante evaluation (i.e., the definition of both a do-nothing and a do-something scenario) is aimed at predicting the mobility situation in Rome without and with implementation of the measures. A set of indicators aimed at defining and measuring the estimated impacts from environmental, transport, and social points of view can be used to compare both the ex ante evaluations (do-nothing and do-something forecasts) and the ex post measurements with the values from the baseline year as an initial evaluation.

The ex post phase represents the second stage of comparison between the before-and-after evaluation activities. This phase can also be considered a means of providing answers to all the questions on the suitability of the measures, but above all, it represents the opportunity to understand whether the hypotheses made while defining the goals are valid (2). Currently, the ex post evaluation is under way and preliminary results are available.

\section{Implementation}

Implementation of this process can be summarized by two key expressions: incentives to attract passengers to transit and disincentives to the use of private cars (3). These expressions are goals that call for two kinds of measures. To increase the attractiveness of transit, interventions have primarily been directed at boosting the use of public transport for home-to-work commuters. Many programs have also been designed to attract all kinds of users to transit, including those traveling for leisure. Each measure is meant to solve a particular challenge in the whole set of problems by using a push-and-pull approach.

A major attempt to increase public awareness of environmental issues was used in conjunction with the traditional attempts to increase the rate of use of transit. Furthermore, long-overdue plans and policies to provide more tailored, innovative public transport systems were introduced to shift travelers toward the use of more sustainable modes of transport. The most important measures and characteristics are briefly described below:

- Collective taxis. Eight collective taxi lines are operating and link the northern districts of the city to downtown.

- Mobility management. One hundred ninety-eight mobility managers have been appointed to plan innovative home-to-work trips involving 268,238 employees; numerous incentives, ranging from discounts for transit tickets to passes for employees of the companies joining the mobility managers' home-to-work shuttle services campaign, are offered. 
- Carpooling. Two pilot case studies are being tested. One comprises a group of 480 municipality employees who have formed 160 carpools, and the other consists of a group 600 employees from the main city hospital who have formed 200 carpooling crews.

- Carsharing. Carsharing started in spring 2005 with a first trial of 200 users who have 11 vehicles in compliance with Euro4 (the European Union emission standard for vehicles) at their disposal.

- Clean transit fleet. A long-term project was begun by providing the transit fleet with 300 new Euro4-compliant buses, along with a trolleybus line.

Automobile restrictions typically comprise disincentives to the use of private cars. This set of measures is aimed at removing private cars from the most sensitive areas of the city, specifically, by enforcing limited traffic zone (LTZ) schemes that have been in place since the end of the 1980s. Currently, LTZ schemes have become more and more refined, and they can be considered the top of a hierarchy of interventions meant to safeguard livability in the historic areas. The features of the LTZ schemes, as well as additional environmentally motivated programs, are listed here:

- Access restrictions. No access to downtown is allowed for drivers without permits (only residents and special categories of drivers are authorized to enter the area) on given days and hours. The access control system (ACS) is based on electronic gates. The gates read the plates of cars accessing the area to determine whether they are allowed to enter. Offenders are fined.

- Optimization of ACS. The electronic gate system has been enhanced and uses dedicated software to update a database of offenders of the access restrictions (the so-called black list).

- Pedestrianization. Some streets around the Spanish Steps area are converted into pedestrian areas.

- Entry of only clean private vehicles to central areas. Only vehicles with catalytic converters can enter the city's central areas; moreover, the yearly inspection of vehicle emissions and the compulsory servicing of motorcycles and mopeds has been extended.

- Road pricing. Permits to travel in the city center can be purchased (flat rate) by some categories of drivers (those participating in commercial activities) or residents who own more than two cars.

- Goods delivery reorganization in central areas. Talks are under way between city authorities and goods operators to reorganize the delivery of goods in central areas. Logistic support has been restructured.

Table 1 shows the main impacts of the measures used to attract passengers to transit and those used to discourage the use of private cars.

\section{MEASURES AND RESULTS}

It is worthwhile to focus on some measures and some of the results, as well as on the process that was used to achieve them. Some measures can be considered extremely relevant in terms of the decisionmaking and implementation processes as well as in terms of the results. These are access restriction, road pricing policies, goods delivery reorganization in the city center, and the use of collective taxis. The results reported in the descriptions of the measures come from simulations, whereas the results achieved so far, as determined from direct measurements after implementation of the measures, will be outlined in the section on the first results.

\section{Access Restriction}

A first access restriction scheme was enforced in 1989, and in 2001 it was turned into an ACS, that is, a set of electronic gates around the historic city center. The main aim was to limit private vehicle access to Rome's central areas, creating an LTZ.

The program was also expected to provide environmental benefits, along with more livable conditions for the inhabitants. Although it was not initially well accepted by the citizens, the measure was successful; the municipality later decided to extend the restriction to San Lorenzo and Trastevere, two districts known for their nightlife. In this case, the LTZ implementers' intention was to ensure accessibility to the areas and to promote the considerable leisure activities. The San Lorenzo LTZ operates from May to October on Wednesdays to Saturdays and from November to April on Fridays and Saturdays (21:00 to 3:00 h). In Trastevere, access restrictions are effective on Fridays and Saturdays $(21: 00$ to $3: 00 \mathrm{~h})$. There are no restrictions for motorcycles or mopeds, people living in the LTZ, and local shopkeepers holding permits.

The effectiveness of the measures was determined by evaluation of their influence on these areas, as well as on their impacts on the transport system, the modal split, and the traffic flow distribution. Furthermore, environmental consequences were also measured. A simulation methodology and a traffic model (a fullfeature geographic information system model designed specifically for planning management and the analysis of transport systems) were applied to complete this evaluation. Two origin-destination (O-D) matrices representing authorized and nonauthorized car user trips and rules of access to LTZs were considered to simulate access restriction results. The model is based on user equilibrium multiclass (i.e., authorized and nonauthorized car users) assignment procedures.

In particular, two simulation scenarios without and with the restriction measures were studied, with the scenarios depicting a kind of do-nothing scenario for the former and a do-something plan for the latter. In the scenario without restriction measures, drivers can travel all area streets without restrictions; in the scenario with restriction measures, the only transportation modes allowed are mopeds, transit, and cars with permits.

The main assumptions of the simulations were as follows:

- Only authorized users can enter the LTZ, and through traffic is forbidden; moreover, no changes of destinations were considered.

- Trips originating from an LTZ are considered unchanged, since there are no restrictions for those departing from the LTZ.

- Authorized drivers entering the areas from 21:00 to 22:00 $\mathrm{h}$ are retailers (given the high number of nighttime commercial activities); other drivers are supposed to shift to transit and mopeds proportionally to the current shares of the other modes. Drivers who want to use their cars are supposed to end their trips at the boundary of the LTZ and park at facilities near the area.

- Because of the ACS and police control, the number of vehicles violating the system was considered negligible in the simulation.

Similar procedures were used in both areas, and the results of the Trastevere case study are reported here; in particular, two O-D matrices representing authorized and nonauthorized car user trips and access rules to LTZ were considered. The simulations with and without the restriction measures analyzed the flow distribution on the network from 21:00 $\mathrm{h}$ to 22:00 $\mathrm{h}$. 
TABLE 1 Types of Measures Targeted to Incentives to Attract Passengers to Transit and to Disincentives to Use of Private Cars and Their Impacts

\begin{tabular}{|c|c|c|c|}
\hline \multirow[b]{2}{*}{ Measure } & \multicolumn{3}{|l|}{ Estimated Impacts On } \\
\hline & Transport & Society & Environment \\
\hline \multicolumn{4}{|c|}{ Incentives to attract passengers to transit } \\
\hline Collective taxis & $\begin{array}{l}\text { Increasing use of collective modes } \\
\text { within } 3 \text { years }\end{array}$ & & \\
\hline Mobility management & & $\begin{array}{l}\text { Increasing public support of } \\
\text { sustainable modes by } 25 \%\end{array}$ & \\
\hline Car pooling & $\begin{array}{l}\text { Attracting a potential user group of } \\
100,000 \text { citizens } \\
\text { Increasing vehicle occupancy for } \\
\text { home-to-work trips by } 20 \%\end{array}$ & & \\
\hline Car sharing & $\begin{array}{l}\text { Reducing car sharer costs by } \\
30 \%-50 \% \text {, thanks to more efficient } \\
\text { use of the vehicle } \\
\text { Increased use of transit } \\
\text { Reducing the number of private cars } \\
\text { by } 10 \%\end{array}$ & $\begin{array}{l}\text { About } 54 \% \text { of users selling their } \\
\text { second car } \\
\text { About } 13 \% \text { of users no longer } \\
\text { purchase a first car }\end{array}$ & \\
\hline Clean transit fleet & & & $\begin{array}{l}\text { Reducing average age of buses } \\
\text { (6.9 years old in } 2005 \text { vs. } \\
12 \text { years old in } 2000)\end{array}$ \\
\hline & & & $\begin{array}{l}\text { Meeting zero-emission standards } \\
\text { requirements }\end{array}$ \\
\hline \multicolumn{4}{|c|}{ Disincentives to the use of private cars } \\
\hline Access restrictions & $\begin{array}{l}\text { Decreasing traffic during the day } \\
\text { by } 10 \% \\
\text { Decreasing traffic during the } \\
\text { restriction period by } 20 \% \\
\text { Decreasing traffic in the morning } \\
\text { peak hour ( } 8: 30-9: 30) \text { by } 15 \% \\
\text { Prevailing PT services in the area } \\
\text { Increasing two wheels by } 10 \%\end{array}$ & & $\begin{array}{l}\text { Reducing pollutant concentration } \\
\text { levels (CO - 20\%, PM10 - 10\% } \\
\text { and benzene - 30\%.) }\end{array}$ \\
\hline $\begin{array}{l}\text { Optimization of the } \\
\text { access control } \\
\text { system }\end{array}$ & & $\begin{array}{l}\text { Reducing the number of offenders } \\
\text { Increasing municipality incomes }\end{array}$ & \\
\hline Pedestrian areas & Reducing road space for cars by $2 \%$ & Raising citizen awareness by $10 \%$ & Reducing the number of polluting \\
\hline $\begin{array}{l}\text { Permits for central } \\
\text { areas only for } \\
\text { clean vehicles }\end{array}$ & Reducing access permits by $4 \%$ & & $\begin{array}{l}\text { vehicles in central areas by } 10 \% \\
\text { and emissions by } 10 \%\end{array}$ \\
\hline Pricing policies & Reducing through traffic & Increasing municipality incomes & Reducing pollution \\
\hline $\begin{array}{l}\text { Goods delivery } \\
\text { distribution }\end{array}$ & $\begin{array}{l}\text { Increasing number of loading/ } \\
\text { unloading areas }\end{array}$ & $\begin{array}{l}\text { Meeting operators requirements } \\
\text { for more accessibility and ease } \\
\text { of delivery }\end{array}$ & \\
\hline
\end{tabular}

In a comparison of the behaviors in approaching the area in the scenario without restriction measures, the majority $(58 \%)$ reach Trastevere by private cars; in the scenario with restriction measures, alternatives to cars are the majority (37\% reach the area by moped and $25 \%$ park at the boundaries). In an analysis of the traffic assignment results, the simulated restriction shows a decrease in flows inside the area and a corresponding increase in flows on the streets nearby caused by route diversions for drivers who previously crossed the area.

The data on the variation in the numbers of vehicle kilometers traveled for different modes caused by implementation of the measures were used to calculate emissions impacts (Figure 1). The levels of pollutants such as $\mathrm{NO}_{x}, \mathrm{CO}_{2}$, and $\mathrm{PM}_{10}$ decrease because of the reduced amount of car use. In contrast, $\mathrm{CO}$ and VOC levels rise because of the higher levels of use of mopeds.
The wider use and high speed of mopeds also increase the number of accidents predicted, represented by the parameter killed and seriously injured (KSI).

\section{Road Pricing Policies}

The ACS mentioned above has been installed to prohibit drivers from entering the city's historic center (the so-called LTZ). Only residents and a few other categories of users (such as disabled people and physicians) can access the area. ACS, together with a flat-fare road pricing scheme for authorized users, is aimed at reducing private car access to the center and at increasing enforcement against illegal access. Environmental benefits can be also expected. Hence, it was important to study how the road pricing scheme influences the traffic 


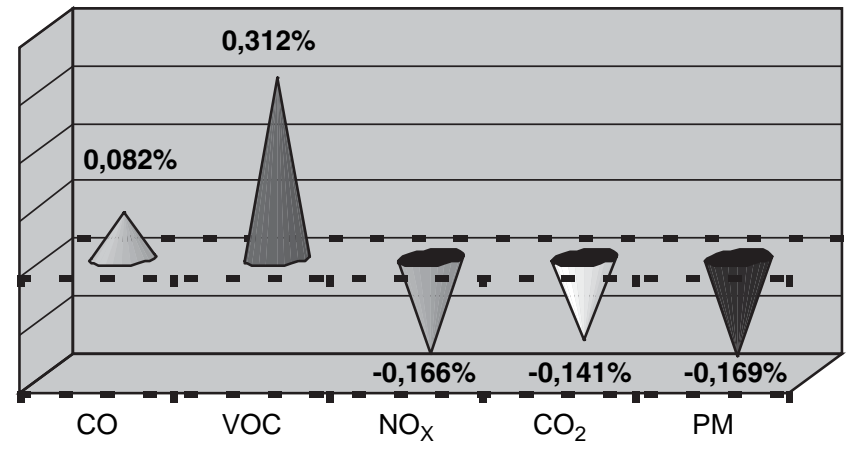

FIGURE 1 Variation of environmental impacts (percentage) as a result of access restriction.

situation in the morning and the afternoon (i.e., periods when access restriction is in effect). It is also important to simulate a road pricing scheme for the evening by taking into account both summer and winter periods. For conciseness, only the morning-afternoon case is described here.

For the morning-afternoon scheme, a simulation model was used to assess how the road pricing policy can affect the modal share, congestion, and externalities of the mobility system. To begin the simulation, activities were focused on surveys consisting of interviews with individuals in different user categories to calibrate the demand model and on-the-spot counts and measurements to calibrate the supply model and to verify the simulation results. A multimodal traffic assignment model was also applied.

These data were used to envisage different road pricing schemes for the LTZ, and they are represented in seven scenarios. Application of access restriction and road pricing implementation was assumed for most of them. The features of each scenario are based on an increase in restrictions and charges, starting from Scenario 0, meant as a do-nothing scenario; all scenarios are summarized in Table 2.

The current parking charge ( $€ 1 / \mathrm{h}$, where $€ 1$ is equal to US $\$ 1.28$ in 2006 dollars) and the stated 4-h stays within the ZTL were also assumed to assess the charges for the seven scenarios.

Another assumption concerned the number of vehicles subject to the charge. Most vehicles entering the ZTL are taxis, ministerial or governmental cars used for official business, and emergency vehicles, that is, vehicles that would not be affected by any road pricing scheme. It has been estimated that there are about 3,800 vehicles in the ZTL in the morning peak period, leaving just about 2,200 vehicles in the morning peak period subject to the charge.

Modal split variations were assessed on the basis of two hypotheses: the first one is based on the integrated approach between access restriction and road pricing, whereas the second one is based on a pure application of road pricing with different charge levels. In the former, overall modal split variations are slight, especially in the first three scenarios (Scenarios 0 to 2), largely because of the low number of cars that can be charged. However, it must be stressed that about $10 \%$ of authorized car users switch to public transport in the event of a $€ 3$ per-trip fare (Scenario 1), whereas an additional $€ 3$ charge (Scenario 2) is required to move $10 \%$ more. About $7 \%$ of the residents switch to transit when they are charged $\mathrm{a} € 300$ annual fare. The effects of charges on mopeds are noticeable in Scenarios 3 to 6 as a result of the reduction of through traffic linked to this category of users. Indeed, when through-traffic trip variations are analyzed, mopeds are the only mode that drastically decreases when they are charged.

In the second case, that is, a pure road pricing application, changes in modal split correspond to different charges; as expected, transit use progressively increases and car use strongly decreases as charges increase. However, it must be noted that these changes occur only in the event of very high — and not realistic — charges of $€ 32$ and $€ 64$ per trip, when the car share switches to $11 \%$ and $8 \%$, respectively.

Environmental impacts due to the application of Scenarios 1 to 6 show clear improvements, particularly in terms of percentages, for the last two scenarios (Scenarios 5 and 6) in the morning peak period. Percent variations are compared with the impacts in Scenario 0.

Safety, represented by the KSI parameter, seems to increase in Scenario 2, when only car pricing is implemented. The explanation hinges on the assumption that, in this case, a substantial number of drivers would opt for mopeds, which are more dangerous than cars (4).

\section{Goods Delivery Reorganization}

Everyday deliveries are another important issue in the mobility scheme of Rome. The amount of freight that enters the city is about 90,000 tons/day; the historic center represents $1.1 \%$ of the urban

TABLE 2 Features of Road Pricing Policy Scenarios

\begin{tabular}{|c|c|c|c|c|c|c|c|}
\hline \multirow[b]{3}{*}{ Scenarios } & \multicolumn{7}{|c|}{ Users Category and Main Attributes } \\
\hline & \multicolumn{2}{|c|}{ Residents Car Users } & \multicolumn{2}{|c|}{$\begin{array}{l}\text { Nonresidents, } \\
\text { Authorized Car Users }\end{array}$} & \multicolumn{2}{|c|}{ Moped Users } & \multirow{2}{*}{$\begin{array}{l}\text { Others } \\
\text { PT Supply } \\
\text { (average trip } \\
\text { reduction) }\end{array}$} \\
\hline & $\begin{array}{l}\text { Charging } \\
\text { Structure }\end{array}$ & $\begin{array}{l}\text { Charge } \\
\text { Level }(€)\end{array}$ & $\begin{array}{l}\text { Charging } \\
\text { Structure }\end{array}$ & $\begin{array}{l}\text { Charge } \\
\text { Level }(€)\end{array}$ & $\begin{array}{l}\text { Charging } \\
\text { Structure }\end{array}$ & $\begin{array}{l}\text { Charge } \\
\text { Level }(€)\end{array}$ & \\
\hline 0 & & & Annual permit & 300 & & & \\
\hline 1 & & & Per trip & 3 & & & $10 \%$ \\
\hline 2 & Annual permit & 300 & Per trip & 6 & & & $20 \%$ \\
\hline 3 & & & Per trip & 1.5 & Per trip & 1.5 & $10 \%$ \\
\hline 4 & & & Per trip & 1.5 & Per trip & 1.5 & $20 \%$ \\
\hline 5 & Annual permit & 300 & Per trip & 6 & Per trip & 1.5 & $20 \%$ \\
\hline 6 & Annual permit & 300 & Per hour & 1.5 & Per trip & 1.5 & $20 \%$ \\
\hline
\end{tabular}


area but attracts $33 \%$ of the total amount of goods delivered. About 25,000 freight vehicles enter the freight LTZ (an area larger than the LTZ) per day. The most striking aspect of this process is the lack of an appropriate number of parking spaces; thus, the municipality's first answer seemed to be just to plan more loading and unloading areas. It was soon evident that this was not the most appropriate solution for the city center, where narrow streets, operators' lack of respect for the rules, and citizens' basic parking requirements make the situation worse day by day.

Hence, a study was conducted to assess the real need for loading and unloading areas in the city center as a prerequisite to whatever other initiatives should be implemented to solve delivery problems on an urban scale. Naturally, the Rome municipality would like to apply the lessons learned in other European cities to improve the logistic system, specifically in the LTZ, to optimize routes. In this context, the identification of suitable loading and unloading area supplies focuses on a comparison between place performance - that is, the characteristics of the loading and unloading areas (location along the street, the size as the number of parking spaces, land use, etc.) in the historic center of Rome-and use demand to define a do-something scenario. The first estimate, which represented an increase in parking space availability by approximately $10 \%$, increased the number of loading and unloading areas from 186 to 201 in 4 years as a result of natural growth in supply but seemed unsatisfactory.

It was therefore necessary to develop a real comparison of the operators' requirements and parking space supply. A study that started with a spot analysis was developed, and an example of how many spaces would be needed in a representative street of the city center is reported as follows. The number of spaces required was estimated by using a coefficient aimed at evaluating the daily attraction of commercial vehicles. The value of this coefficient varies with each kind of commercial activity and was obtained from interviews with retailers. For each of the streets analyzed, the number of spaces ranged from 3 to 14 ; a counting survey of commercial vehicles operating on the streets confirmed the results obtained by use of the attractiveness coefficient.

Residents' parking requirements were also taken into account because the creation of new bays for deliveries often results in fewer parking spaces for residents.

With the results obtained to the downtown level expanded, it has been estimated that about 600 new spaces are required, in accordance with the current development of the city and consistent with the commercial high-density nature of the area. This number of spaces was confirmed by an informal analysis of the results of municipal planning directions.

An important issue emerging from this study is the mandate to meet parking requirements. With provision of this basic requirement, every other intervention is possible. In Rome, given the poor supply of loading and unloading areas for commercial activities, any extra action in terms of fleet renewal, e-commerce development, the provision of logistic platform locations, and so on must be postponed until the loading supply question is addressed. Another point to be considered is the local operators' general wariness; they are not ready for negotiations, so it is difficult to have proper knowledge of their requirements. Furthermore, historic urban features and dense land use greatly complicate delivery system networks in historic city centers. Political will is required in terms of both the measures to be implemented and the acceptance of disincentives, but political measures are not sufficient when the built environment has a premium value. Typically, in this case, the provision of loading and unloading areas is poor, and conflicts between residents and operators are likely to arise. In this case, only a relative optimum can be reached for each solution.

\section{Collective Taxis}

Collective taxis were initially operated without any planning. The service was therefore reorganized by the Società Trasporti Automobilistici (Car Transportation Society), a company that was appointed by the Rome municipality to manage certain mobility services, such as traffic control, payment for parking, clamps for illegal parking, and that set a minimum number of vehicles and service quality standards for collective taxi operators. In accordance with these standards, in 2000, three privately operated lines with highquality collective taxi service (eight passengers plus a driver), called Taxibus, started operating; and a fourth line was implemented in 2003. Taxibus connects some northern districts of the city to downtown, and despite its small extent (the main performance characteristics of the lines are reported in Table 3), it can be considered a successful measure, with its attractiveness resulting from its ease of use and reliability. This service represents a kind of business class for bus and metro users who are willing to pay a little more (but less than the cost of a taxi) to arrive on time, close to their destination, and in comfort, especially in poor weather conditions.

As a result of the positive results in the initial phase, the next step was to improve the service supply by adding new connections. The main objectives in the design of the new lines are reported here. The objectives were drawn up according to the analysis of the results of the current situation and in particular try to enhance existing lines and create new ones. To achieve these aims, strong attention was paid to the results of customer care analyses in terms of both the level of satisfaction and users' acceptance of different payment possibilities (a single ticket or a travel pass). It was necessary to know how passengers felt about this service before new service options were developed. In particular, the most

TABLE 3 Performance Characteristics of Four Collective Taxi Lines in First Period of Operations

\begin{tabular}{lccccccccc}
\hline $\begin{array}{l}\text { Line } \\
\text { Number }\end{array}$ & $\begin{array}{l}\text { Length } \\
(\mathrm{km})\end{array}$ & $\begin{array}{l}\text { Travel } \\
\text { Time } \\
(\mathrm{min})\end{array}$ & $\begin{array}{l}\text { Frequency } \\
(\mathrm{TU} / \mathrm{h})\end{array}$ & $\begin{array}{l}\text { Seats/ } \\
\text { Day }\end{array}$ & $\begin{array}{l}\text { Pass/ } \\
\text { Day }\end{array}$ & $\begin{array}{l}\text { Veh } \\
\mathrm{km} / \text { day }\end{array}$ & $\begin{array}{l}\text { Seats } \\
\mathrm{km} / \mathrm{day}\end{array}$ & $\begin{array}{l}\text { Pass } \\
\mathrm{km} / \text { day }\end{array}$ & $\begin{array}{l}\text { Load } \\
\text { Factor } \\
(\%)\end{array}$ \\
\hline 1 & 7.6 & 20 & 4 & 832 & 291 & 729.6 & 5,837 & 1,926 & 33 \\
2 & 8.1 & 20 & $3-4$ & 600 & 225 & 583.2 & 4,666 & 1,680 & 36 \\
3 & 7.5 & 20 & 3 & 624 & 193 & 540.0 & 4,320 & 1,296 & 30 \\
4 & 9.7 & 35 & 4 & 864 & 70 & 698.4 & 5,587 & 447 & 8 \\
Total & 32.9 & & - & 2,920 & 779 & $2,551.2$ & 20,410 & 5,349 & - \\
\hline
\end{tabular}

Veh = vehicles; pass $=$ passengers $; \mathrm{TU}=$ transit unit. 
important aspect was the willingness to pay, that is, the willingness to spend more to get better service, especially by potential customers. The results showed that $50 \%$ would agree to pay the public transport fare (the one-way, 75-min public transport fare is currently $€ 1$ ), $27 \%$ would pay up to $€ 3$, and $4 \%$ would even pay a charge comparable to that for a taxi or more.

Service extension was based on two core objectives: the frequencies of the existing lines should be increased and spatial, temporal, and operating flexibility should be enhanced. For instance, an improved booking system (by telephone, text message, or web) would allow minor route diversions to reduce ancillary walking to Taxibus stops for elderly and disabled individuals (all vehicles are fully accessible by wheelchair).

The core of the study was to outline the economic feasibility of the service on the four new lines. With the design of new routes on the map, the next step was to define an operating plan to assess service performance for a 3-year period. Moreover, some crucial features noted in the study of the lines already in operation, such as the need for a greater frequency and spatial flexibility, had to be taken into account.

The operating plan differs from year to year according to the level of service supplied and increases until the third year, when the potential demand is fully met. It was not realistic to expect demand to reach target levels in a shorter period, as it takes a long time to attract new customers to a service, and in some areas this service was absolutely innovative and virtually unknown.

Rough evaluations were used to quantify traffic flows on the basis of the 1991 national census data to calculate potential daily demand. For this purpose, among the total daily flows for work and school trips in the whole area of Rome, only private cars trips (about $61 \%$ of all trips) were considered. Data were updated to 2001; and a peak-period flow, about $12 \%$ of the total daily demand, was assumed. Finally, only the flows related to the area of implementation were considered. Quantification of attractable customer demand was determined by calculating only the number of customers who were disposed to pay more than the cost of a bus trip. The decision to consider only private car users as potential patrons is mainly based on social and environmental reasons, that is, the large number of shifts from private cars (a switch to a faster and more reliable service than public transport) and the high level of pollution caused by private cars, respectively. Table 4 shows the demand trends according to short-term and medium- to long-term scenarios, calculated as described above.

Starting from the operation of four lines, four extra lines operating in the northwest area of the city were analyzed; these lines were assigned to private operators for 3 years by the local transit company and the Rome municipality transport agency. Despite their current user success, collective taxis remain a niche form of transit without a strong impact on travel patterns in Rome; if mere facts are considered, these two transit options are not comparable because 100,000 passengers travel in collective taxis each year, whereas 873 million passengers travel by bus; thus, about 3 million vehicle kilometers per year are carried by the collective taxis, whereas 133 million vehicle kilometers per year are carried by buses. The relevance of collective taxis is still referable to the neighborhood level and not to the community level, but such positive results will pave the way for major implementation at the urban level.

\section{First Results}

Preliminary results are available for all the measures described above. Although they are not consolidated results, they can provide an indication on how the situation in Rome could improve if the synergy resulting from application of the measures based on incentives to attract passengers to transit and disincentives to the use of private cars were pursued. According to the Miracles methodology, the results from the synergistic application of all measures were assessed to determine their environmental, transport, and social benefits.

From an environmental point of view, comparison of the mean pollutant concentrations and emissions measured in 2001 and those measured in 2004 showed an appreciable reduction in concentrations $\left(-21 \%\right.$ for $\mathrm{CO},-11 \%$ for $\mathrm{PM}_{10}$, and $-37 \%$ for benzene) and emissions ( $-39 \%$ for $\mathrm{PM}_{10}$ and benzene and $-20 \%$ for $\mathrm{CO}$ ), as well as a $40 \%$ reduction in the number of polluting vehicles. All these values exceeded expectations, as shown by comparison with the estimated results reported in Table 1. This positive outcome can be considered a combined effect of all measures, but perhaps the greatest benefits come from permitting only clean private vehicles to enter central areas.

The impacts on transport were also assessed and were found to be positive. The modal split for just the urban area (which is smaller than the metropolitan one, which includes satellite and rural areas) in 2002 was $30 \%$ transit, $27 \%$ private cars, $23 \%$ two-wheelers, and $20 \%$ pedestrians; according to ex post surveys, they are currently $31 \%$ transit, $22 \%$ private cars, $24 \%$ two-wheelers, and $23 \%$ pedestrians. A 5 percentage point decrease for private cars in favor of a 3 percentage point increase for walking can be considered a

TABLE 4 Overall Network Demand Trends for Collective Taxis

\begin{tabular}{|c|c|c|c|c|c|c|}
\hline $\begin{array}{l}\text { Line } \\
\text { Number }\end{array}$ & $\begin{array}{l}\text { Length } \\
(\mathrm{km})\end{array}$ & $\begin{array}{l}\text { Travel } \\
\text { Time } \\
\text { (min) }\end{array}$ & $\begin{array}{l}\text { Daily Short } \\
\text { Term } \\
\text { Demand } \\
\text { (pass/day) }\end{array}$ & $\begin{array}{l}\text { Daily Medium- } \\
\text { Long Term } \\
\text { Demand } \\
\text { (pass/day) }\end{array}$ & $\begin{array}{l}\text { Medium-Long } \\
\text { Term Demand } \\
\text { Peak Hour } \\
\text { (pass/h) }\end{array}$ & $\begin{array}{l}\text { Frequency } \\
\text { Peak Hour } \\
\text { (TU/h) }\end{array}$ \\
\hline 1 & 7.6 & 20 & 298 & 397 & 48 & 6 \\
\hline 2 & 8.1 & 20 & 296 & 492 & 60 & 8 \\
\hline 3 & 7.5 & 20 & 195 & 212 & 26 & 4 \\
\hline 4 & 9.7 & 35 & 326 & 652 & 79 & 10 \\
\hline 5 & 10 & 35 & 150 & 249 & 30 & 4 \\
\hline 6 & 7.6 & 20 & 398 & 637 & 77 & 10 \\
\hline 7 & 10.8 & 35 & 359 & 717 & 87 & 11 \\
\hline 8 & 10.5 & 35 & 299 & 497 & 60 & 8 \\
\hline Total & 72.4 & - & 2321 & 3853 & & \\
\hline
\end{tabular}


noteworthy result because it probably means that citizens are getting tired of short car trips. Access restrictions and pedestrianization were the main drivers of such achievements: in particular, the former decreased traffic flows during the restriction periods by $20 \%$ and reduced illegal through traffic by $25 \%$ in central areas.

The changes in the public's perception of the new mobility policy are also interesting: the rates of awareness and acceptance of the measures, such as the conversion of the transit fleet to cleaner vehicles and the need for the use of collective taxis or carsharing (from which everyone can benefit), have dramatically risen, thus demonstrating a positive attitude toward green modes and sustainability issues in general. On the contrary, the measures that Romans perceived to be limitations of their own freedom to move, that is, access restrictions and pricing, are still not fully accepted, with their share of acceptance among people being strongly decreased. In particular, if the satisfaction rates for access restriction between 2002 and 2006 are compared (according to customer care surveys run as part of Miracles), citizens' approval of the measure has dropped markedly (more than a half point on a 1- to 5-point Lickert scale). Thus, the assessment shows that the response to the policy has been moderately positive. Innovation has a great impact; in effect, although Romans are getting used to the restrictions, their rates of satisfaction with the use of measures such as collective taxis and carsharing are incredibly positive (more than 3 points on the Lickert scale).

\section{IMPLEMENTATION PROCESS}

The measures described above would never have been implemented in a straightforward manner if the municipality had not been involved in the Miracles project. Thanks to the Miracles project, it was possible to start $(a)$ simulating most of the measures that were still at the planning level, such as road pricing and goods delivery reorganization, and (b) to support measures still at the early stages, such as access restriction and collective taxis. In particular, good results from modeling, for instance, the expected reduction of pollutant emissions because of access restriction, prompted local administrators to start evaluating the feasibility of scaling up the measures to other urban areas.

Therefore, the current political trend is to keep supporting the implementation of the measures that have already been applied and to convert the good results from the simulations into the implementation of new interventions consisting of measures still at the feasibility evaluation stage. Such progress is also supported by some recent national regulations whose intent is to promote the use of alternatives to private cars and to create incentives for the use of new forms of transit in urban areas.

\section{CONCLUSIONS}

The restriction of traffic or the use of road pricing measures is targeted at reducing the widespread use of private cars. If these are considered to work in synergy with the incentives to use transit (with an increase in the numbers of collective taxis and the conversion of the transit fleet to clean vehicles) and with measures aimed at raising people's awareness of more sustainable mobility patterns, the most important results so far have shown positive advantages in terms of improved environmental conditions and livability.

The lesson to be learned from these initial findings is that citizens judge disincentives to use private cars as less positive than incentives to attract passengers to transit, even if environmental benefits are evident from the do-something simulation and are confirmed by ex post surveys. The reason could be that car culture habits are still strong, and such a culture prevents decision makers from looking for options other than car-based ones. Consequently, citizens have no real modal choice. Possible open questions, hence, will concern how individuals at the political level can discourage the use of private cars: whether the approach must be based on restrictions, as currently applied, or whether more popular incentives must be supported to attract passengers to transit. The challenge could therefore be based on the creation of more attentive behaviors among private car drivers as a result of an overall increase in sustainability.

\section{ACKNOWLEDGMENT}

The authors thank Luca Persia of the Società Italiana Docenti di Trasporti (Italian Society of Transportation Academic Staff) for providing data and information on access restriction and road pricing.

\section{REFERENCES}

1. Valutazione delle Emissioni Inquinanti Prodotte dal Traffico Veicolare. Rome Municipality Annual Report. Environmental Policies Department, Rome Municipality, Rome, 2002.

2. Musso, A., and M. V. Corazza. Miracles: Metodologia, Tecnologia, Innovazione. Il Caso di Roma. Proc., Società Italiana Docenti di Trasporti Seminar, Reggio Calabria, Italy, 2005.

3. Vuchic, V. R. Transport for Livable Cities. Center for Urban Policy Research, Rutgers University, New Brunswick, N.J., 1999.

4. Filippi, F., and L. Persia. Final Demonstration Implementation Report. PROGRESS Report Deliverable 5.2. www.progress-project.org. Accessed July 2005.

The Transportation Demand Management Committee sponsored publication of this paper. 